\title{
Alographia dos álkalis... DE FREI CONCEIÇÃO VELOSO: UM MANUAL DE QUÍMICA INDUSTRIAL PARA PRODUÇÃO DA POTASSA NO BRASIL COLONIAL
}

\author{
Fernando J. Luna \\ Goytacazes - RJ, Brasil \\ Recebido em 3/3/08; aceito em 6/5/08; publicado na web em 5/11/08
}

Centro de Ciência e Tecnologia, Universidade Estadual do Norte Fluminense, Av. Alberto Lamego, 2000, 28013-602 Campos dos

\begin{abstract}
THE PRODUCTION OF POTASH FROM PLANTS IN COLONIAL BRAZIL AS DESCRIBED IN FRAY CONCEIÇÃO VELOSO'S Alographia dos alkalis... Potassium carbonate, or potash, was the most important industrial chemical of the $18^{\text {th }}$ century. It was essential for producing glass, soap, saltpeter, dyes, several drugs, and also used for bleaching linens, paper, and sugar. We examine here a book in which Brazilian author José Mariano da Conceição Veloso gathered his translations into Portuguese of English and French articles, letters, patents, and pamphlets with instructions on how to prepare potash. We discuss especially his version of Richard Watson's essay entitled 'Of saline substances', and Veloso's own 'Flora Alographica', a description of the Brazilian plants that could be used to prepare potash.
\end{abstract}

Keywords: history of technology; science in Brazil; Portuguese Empire.

\section{INTRODUÇÃO}

A característica determinante do governo de D. José I, rei de Portugal entre 1750 e 1777 , foi seu empenho em modernizar o império de acordo com as idéias iluministas surgidas nos países centrais da Europa: França, Inglaterra, Alemanha, Holanda e Itália. A era das grandes descobertas nos séculos XV e XVI foi seguida por um longo declínio que se estendeu até meados do século XVIII, quando tomou as rédeas do governo o Marquês de Pombal (1699-1782). Do ponto de vista econômico, a administração de Pombal foi marcada pelo fortalecimento do Estado e por uma política de incentivo à industrialização da economia para fazer frente à crise grave causada, sobretudo, pelo declínio da mineração do ouro brasileiro. Um dos resultados dessa política de Pombal foi o surgimento, em Portugal, de uma incipiente comunidade científica, especialmente depois da reforma realizada na Universidade de Coimbra, em 1772, e da contratação dos italianos Domenico Vandelli (1735-1816), químico e botânico, e Giovanni Antonio Dalla Bella (1730-ca. 1823), professor de física. A implementação dessas reformas contemplava tanto aspectos filosóficos e pedagógicos, com a impressão e circulação de livros visando a introdução do modo de pensar moderno, quanto o aspecto prático, que demandava a publicação de "Memórias", artigos, patentes e manuais de tecnologia com o intuito de fomentar a produção de matérias-primas que pudessem modernizar a agricultura e acelerar o processo de industrialização de Portugal. ${ }^{1}$

Desde os tempos mais remotos, a fabricação de vidro e de sabão, dois produtos de indiscutível importância econômica, dependeu do carbonato de potássio, conhecido historicamente como potassa. De acordo com a Historia Naturalis, a enciclopédia de ciência e tecnologia escrita pelo romano Plínio, o Velho (23-79), que manteve influência sobre o conhecimento no Ocidente por mais de mil anos, ${ }^{2}$ o vidro teria sido inventado por serendipidade na Síria, ${ }^{3}$ assim como Plíssio atribui aos franceses a invenção do sabão pela combinação de sebo animal com os sais obtidos a partir da queima de determinadas plantas. ${ }^{4}$ No século XIX, a potassa passou a ser o principal insumo da indústria química por ser matéria-prima essencial para, além do

*e-mail: fernando@uenf.br vidro e do sabão, o branqueamento de tecidos, de papel, do açúcar, ${ }^{5}$ e no preparo de medicamentos e tinturas. ${ }^{6}$ Neste artigo o objetivo foi mostrar como frei José Mariano da Conceição Veloso discute a técnica industrial de obtenção do carbonato de potássio a partir de plantas no seu livro denominado Alographia dos álcalis fixos vegetal ou potassa, mineral ou soda e dos seus nitratos, segundo as melhores memorias estrangeiras, Que se tem escripto a este assumpto parte primeira, ${ }^{7}$ publicado em 1798 em Lisboa. Note-se que as referências à obtenção de potassa não são particularmente raras na literatura dos cronistas do Brasil colonial, escrita ao longo dos dois séculos anteriores, ${ }^{8}$ e no Brasil pré-colombiano os índios "embora não fossem amantes do sal como condimento, é certo que o sabiam extrair da raiz de carnaúba calcinada". ${ }^{9}$ Enfocamos aqui, principalmente, a primeira seção da obra, i.e., a tradução de um dos ensaios de Richard Watson (1737-1816), professor de química em Cambridge, onde introduz os conceitos já bem estabelecidos de sais ácidos, alcalinos e neutros. Discutimos também a seção intitulada 'flora alographica', de autoria do próprio Veloso, em que apresenta a classificação taxonômica das plantas brasileiras que poderiam ser usadas na produção da potassa.

Nascido em Minas Gerais, ${ }^{11}$ Veloso tornou-se frade no convento de $\mathrm{S}$. Boaventura ${ }^{12}$ e dedicou-se à botânica, especialidade em que os franciscanos guardam longa tradição, ${ }^{13}$ no convento de Santo Antonio,

Fr. Tosé Marianno da Concei,ge Pclloso, Ex-Provincial dos Religiosos Fransiscanoj Reformados da Provincis da Conceiçăo do Rio de Faneiro, e Botanico Pensionado por S. A. R. o Principe Rezente nosso Senhor, faleceo de hydropesia anasarci no seu Convento de Santo Antorio dests Cidade, tendo de idade 69 annos. Emprezando zo e tantos annos de estutos na vast.ssima sciencia da Historic $\mathrm{Na}$ szrai, este Varáo de excellente engenho compôz, depois de immensas fadigas pelos ser:öes da Americas, a Flora do Rio le Zanciro, Obro de 11 volumes em fol., onde se acháo analysa tas mais de 3 plantas, e classificidas sezundo o systema de Linteo. Esta Obra vai a publicar-se, e ella furá con que o seu nome passe a mais remora posteridsde com gloria dos nossos, e inveja dos estranlios, de quem já he conhecido e cirado, cumo se vê do Compendio de willdenciv, Botanico Alemĭo, e hum dos mais celebres do seculo presence. A brilhance caneir docre sabio Relig:oso foi hum mais cele continuado servico da Patria para quem sua morre he htima verdade:ra perda : e todos os que admiráráo a sua instrucçáo nada vulgat, intzireza de costumes, e amenidade de conversaçáo, náo podem facilmente apaşar a saudade produzida pela sua Galtag.

Figura 1. Elogiosa nota de falecimento de Veloso publicada em 22 de junho de 1811 na Gazeta do Rio de Janeiro, primeiro jornal impresso no Brasillo 
no centro da cidade do Rio de Janeiro. Entre outras disciplinas foi professor de história natural, até que o vice-rei Luiz de Vasconcelos e Souza (1742-1809) o designou para liderar 40 pessoas, entre as quais metade de escravos, em uma expedição botânica (1779-1790) pelo interior do Rio de Janeiro, considerada a primeira do gênero na parte sul do país, realizada na mesma época da memorável Viagem Filosófica de Alexandre Rodrigues Ferreira. ${ }^{14}$ Viajou a Portugal em 1790 para se tornar o primeiro diretor da mais importante instituição oficial de edição de livros de Lisboa, a Tipographia Real Calcográfica do Arco do Cego; trabalhou também no Real Museu e Jardim da Ajuda e na Academia Real das Ciências de Lisboa, enquanto preparava a publicação de Florae Fluminensis, sua obra mais significativa. Em 1809, voltou ao Brasil acompanhando a fuga da família real e morreu dois anos depois, como se pode ler no necrológio mostrado na Figura $1 .{ }^{15}$

\section{Produção da potassa a partir de plantas}

A existência de vários termos para se referir a uma mesma substância simples, ainda que freqüentemente impura por causa dos métodos rudimentares de obtenção, deve ser abordada por razões de clareza. No século XVIII, a potassa, a soda, a barita, a estroncita, a cal e o amoníaco eram considerados diferentes tipos de álcalis. Dentre estes, distinguiam-se, por sua importância industrial, os 'sais alcalinos fixos', que eram a soda e a potassa, porque resistem à ação do fogo e ao sal alcalino volátil, i.e., o amoníaco ou hidróxido de amônio, assim denominado porque evapora ao ser submetido ao calor.

A potassa e a soda eram produzidas em larga escala pela queima de certos tipos de plantas até quando teve início a exploração dos depósitos minerais de Stassfurt na Alemanha, em $1861,{ }^{16}$ e com a disseminação do processo Leblanc de produção industrial de carbonato de potássio na primeira metade do século XIX, que fez desaparecer a produção dessa matéria-prima pela queima de plantas. A potassa era mais barata que a barrilha, mas à medida que a demanda por sabão e vidro aumentava e as florestas diminuíam, o processo de obtenção por queima de madeira foi-se tornando cada vez menos apropriado. ${ }^{17}$

Tabela 1. Explicação de alguns termos encontrados na literatura química do século XVIII

\begin{tabular}{|c|c|c|}
\hline denominação arcaica & $\begin{array}{c}\text { método de obtenção no } \\
\text { séc. XVIII }\end{array}$ & fórmula \\
\hline $\begin{array}{l}\text { álcali fixo mineral, } \\
\text { soda, barrilha }\end{array}$ & $\begin{array}{c}\text { queima de algas } \\
\text { marinhas ou plantas } \\
\text { costeiras ricas em sódio }\end{array}$ & $\mathrm{Na}_{2} \mathrm{CO}_{3}$ \\
\hline $\begin{array}{l}\text { álcali fixo vegetal, } \\
\text { potassa }\end{array}$ & $\begin{array}{l}\text { queima de plantas } \\
\text { ricas em potássio }\end{array}$ & $\mathrm{K}_{2} \mathrm{CO}_{3}$ \\
\hline $\begin{array}{l}\text { natrão, trona, natro, } \\
\text { soda egípcia }\end{array}$ & $\begin{array}{c}\text { depósitos minerais no } \\
\text { Egito }\end{array}$ & $\mathrm{Na}_{2} \mathrm{CO}_{3} \cdot 10 \mathrm{H}_{2} \mathrm{O}$ \\
\hline sal alcalino volátil & destilação de urina & $\mathrm{NH}_{4} \mathrm{OH}$ \\
\hline potassa cáustica & $\mathrm{K}_{2} \mathrm{CO}_{3}+\mathrm{Ca}(\mathrm{OH})_{2}$ & $\mathrm{KOH}$ \\
\hline salitre, nitro & $\begin{array}{c}\text { depósitos minerais, } \\
\text { salitreiras }\end{array}$ & $\mathrm{KNO}_{3}$ \\
\hline
\end{tabular}

Na Tabela 1 são explicados alguns termos arcaicos encontrados na literatura química no período histórico abordado neste artigo. No final do século XVIII, já era bem estabelecida a diferença entre soda e potassa, ou seja, entre $\mathrm{Na}_{2} \mathrm{CO}_{3}$ e $\mathrm{K}_{2} \mathrm{CO}_{3}$, respectivamente. Bem antes disso, segundo Thompson, ${ }^{18}$ já no final do século $\mathrm{X}$ o alquimista persa Abu Mansur Muwaffah havia feito a distinção entre carbonato de sódio e carbonato de potássio, afirmando que este último é um sólido branco deliqüescente de sabor cáustico e que podia ser obtido a partir de certas plantas. Há um artigo chamado Sur la base du sel Marin, ${ }^{19}$ publicado em 1736, em que Henri-Louis Duhamel du Monceau $(1700-1782)^{20}$ demonstra a existência de diferentes tipos de álcalis, mas foi Claude-Joseph Geoffroy (1685-1752)21 o primeiro químico moderno a confirmar, em 1724, as observações do alquimista persa. ${ }^{22}$ Uma edição coeva da Encyclopédie ${ }^{23}$ esclarece que a palavra 'potassa' significava, originalmente, 'cinzas de panela' e define a potassa como "um sal alcalino fixo que se retira das cinzas de diferentes tipos de madeira queimada, e que se dá também o nome de potassa à própria cinza que contém o sal alcalino fixo; esta cinza é tornada compacta e sólida como uma pedra, porque se lhe umidifica para este efeito com água, após o que calcina-se para endurecê-la [...]". ${ }^{24}$ Manuel Arruda da Câmara (1752-1811), naturalista pernambucano que teria traduzido o Traité Elementaire de Chimie sob orientação de Lavoisier (17431794), ${ }^{25}$ em um artigo publicado em 1814, afirma que soda, 'alkali mineral' e 'natrum' são sinônimos e o adjetivo 'mineral' aplica-se porque pode ser "achada no seio da terra, e na sua superfície". ${ }^{26}$

As fontes mais ricas de soda eram as algas marinhas e as plantas encontradas próximo à água salgada, especialmente o arbusto Salsola soda L., típico da costa mediterrânea espanhola e conhecida historicamente como barrilha, cujo conteúdo de carbonato de sódio alcança os $20 \%$. Esta espécie nativa da Espanha apresenta níveis superiores (12 a 20\%) de carbonato de sódio, quando se compara às algas marinhas, que contêm entre 5 e $8 \% .{ }^{27}$ Enquanto a potassa podia ser produzida a partir de quase todos os tipos de plantas herbáceas, cujos tecidos apresentam pouca ou nenhuma lignina, a soda ou barrilha ${ }^{28}$ somente era obtida a partir das chamadas barrilheiras. ${ }^{29}$ Essas plantas vivem em salinas, lagos salgados, restingas e solos impregnados com água do mar, como explica Arruda da Câmara na sua "memória sobre as plantas que se pode fazer barrilha entre nós" ${ }^{30}$ quando afirma que a

cultura da planta da barrilha é bem simples: basta ter-se limpo o terreno em que se pretenda semear, e depois de lavrado deitar a semente, passando-lhe a grade do mesmo modo que nas sementeiras ordinárias; só tem uma circunstância a cultura da barrilha, a qual se o agricultor não atende, todo o seu trabalho fica frustrado; esta circunstância é de semear sempre a barrilha ao pé d'água salgada, principalmente em lugares alagadiços.

Esse tipo de meio ambiente é muito seletivo e abriga espécies altamente especializadas, que estão adaptadas fisiologicamente a condições extremas de sobrevivência. Dentre os vários mecanismos dos quais as plantas se valem para se adaptar ao estresse salino em ambientes salsuginosos, alguns causam o acúmulo de alta concentração de sódio observado depois de queimadas. A diluição da alta concentração salina nos tecidos da planta por crescimento e formação de suculentos, que depende da flexibilidade das paredes celulares, é um dos mecanismos utilizados por esse tipo de plantas. Dajic ${ }^{31}$ explica que, em alguns casos, as plantas possuem um sistema de excreção salina composto por glândulas foliares que compartimentalizam os sais de maneira ativa. Em outros casos, têm a possibilidade de aumentar o conteúdo de água nas folhas com o objetivo de evitar a queda no potencial osmótico, que ocorre com o aumento excessivo da concentração salina.

No periódico brasileiro chamado Auxiliador da Indústria Nacional, publicado de 1833 a 1892, que consistiu na mais importante fonte de textos avulsos sobre tecnologia para a agricultura e a indústria, há um artigo cujo autor não é identificado onde se encontram algumas definições pertinentes, senão vejamos: decoada é "o liquido, que resulta da filtração da água pelas cinzas"; perlassa é "o resíduo, que no 
fundo da caldeira deixa a decoada evaporada ao fogo, o qual esfriando toma a apparencia de sal de differentes cores, segundo as cinzas, de que foi feita a decoada"; potassa é "este mesmo sal calcinado ao fogo, por cuja operação se torna esbranquiçado". ${ }^{32}$ Um outro termo cuja definição nos interessa é o de 'cinza gravelada', que pode ser encontrada na própria Alographia... "chamam-se gravellas as borras do vinho seccas, queimando-se e calcinando-se estas substâncias [...] se chama a este Sal Cinza gravellada. Purifica-se do mesmo modo que a potassa". O sal alcalino obtido da borra de vinho dessa forma "he livre, e puro de toda a mistura de sal neutro". ${ }^{33}$

\section{A Alographia dos alkalis fixos... de Frei Veloso}

O livro intitulado Alographia dos alkalis fixos vegetal ou potassa, mineral ou soda e dos seus nitratos, segundo as melhores memorias estrangeiras, Que se tem escripto a este assumpto parte primeira tem 245 páginas numeradas e foi publicado em 1798, em Lisboa, na Oficina de Simão Thaddeo Ferreira, ${ }^{34}$ somente um ano antes da fundação da Tipografia do Arco do Cego, que Veloso iria dirigir. ${ }^{35}$ No início do volume, um "aviso ao leitor" explica que se deu o nome de "Alographia por tratar sobre a natureza dos Saes"36 - a palavra sal em grego é háls, de que se origina o termo haleto, por exemplo. ${ }^{37}$ Veloso reuniu neste volume as traduções de capítulos de livros, cartas enviadas a sociedades científicas, artigos de periódicos científicos, patentes, a planta baixa de uma fábrica de potassa, um verbete da Encyclopédie de Diderot e D’Alembert, estampas com ilustrações detalhadas dos fornos que deveriam ser usados na produção da potassa, além de desenhos das plantas brasileiras que poderiam ser usadas para este propósito. Uma visão geral da obra é mostrada na Tabela 2.

Tabela 2. Visão geral do livro Alographia dos alkalis fixos vegetal ou potassa... com explicações sobre as fontes usadas por Veloso

\begin{tabular}{cccc}
\hline Pág. & Título da seção como consta na & fonte original & autor \\
\hline
\end{tabular}

$1 \quad$ Memória sobre os alkalis by R. Watson

D.D.F.R. professor régio de theologia da

Chemical Essais, Tom I. Essais III Richard Watson (1737-1816)

capítulo de livro

Universidade de Cambridge

17 Extracto do catalogo methodico, e explicado da collecção dos fossis, ou cavadiços pertencente a illustrissima Leonor de Raab Declaraçao do privilegio concedido a Jorge Glenni de Bromley Hill no districto de Kent pelo seu methodo de obter das cinzas dos combustiveis vegetaes huma maior quantidade de Potassa Prémios offerecidos em Inglaterra, a quem fizesse a Potassa, e Perlassa

COPIA de huma carta escrita aos Editores do Museum Rusticum et Commerc. por J. R. de Stow Mark Suffolk aos 4 de Junho de 1764

61 Extracto do No XI Procedimento para se fazer a Potassa communicado por M.

Dossie à Sociedade para o adiantamento da Artes, etc

79 COPIA de huma segunda carta de Mr. Dossie

88 Extracto da seccao VIII dos Elementos de Chymica de M. Chaptal

95 Extracto sobre o methodo de se preparar a potassa (encyclopedie methodique)

111 Experimentos das substancias alkalinas usadas na branqueacao, e materias colorantes dos linhos by Richard Kiruan esq.

142 Especificacao do privilegio concedido ao Conde Dundonald pelo seu methodo ou methodos de se prepara e obter hum alkali ou soda

159 instruccao sobre a combustao dos vegetaes para a factura do alkali vegetal, das cinzas gravelladas [...]

185 Explicação das estampas

191 flora alographica

Catalogue méthod. et raisonné de la..

Catalogue mêthod. et raisonné de la.

The repertory of Arts and Manufactures \&c. Vol 2. pág. 178

George Glenny patente inglesa

Museum Rusticum et commerciale

Museum Rusticum et commerciale

Society for the Encouragement Arts, Manuf. \& Commerce

$?$

Museum Rusticum et commerciale

Robert Dossie (1717-1777)

Artigo

idem

Élemens de Chimie
Encyclopédie
Repertory of Arts and
Manufacture Tom V
Repertory of Arts and
Manufacture

"de hum folheto francez de 1794."

$?$

Jean-Antoine-Claude Chaptal (1756-1832)

Diderot e D'Alembert

Richard Kirwan

Archibald Cochrane (1748-1831)

patente

carta

excerto de livro verbete da Éncyclopédie artigo

anúncio em periódico científico carta em periódico

\section{rtigo}

“

$$
\text { 1791) }
$$


Na introdução, em que se dirige diretamente ao Príncipe Regente D. João (1767-1826), Veloso escreve que depois do trabalho realizado por determinação real dentro de um período "não excedendo o de três meses, se achão quasi impressas acima de mil páginas". Diz também que "levantando-se as fabricas dos três Saes, que se propõe nesta Obra, que são precisos, não só ellas em si pouparão muito numerário, que annualmente se extravia deste Reino para o Norte da Europa, e da América, India, e Hespanha, mas também o adquirirão ás nossas Saboarias, Vidrarias, Tinturarias, Branquearias, á Agricultura, á Chymica, a Pharmacia, \& c." ${ }^{38}$ Do periódico inglês chamado Museum Rusticum et Commerciale ${ }^{39}$ publicado pela Royal Society for the Encouragement of Arts, Manufactures and Commerce, fundada em 1754 para estimular a indústria e a agricultura por meio de prêmios monetários, menções honrosas e a difusão do conhecimento, ${ }^{40}$ há a tradução de uma carta de um fazendeiro inglês com instruções detalhadas para o fabrico da potassa, além do anúncio de prêmios oferecidos pela Sociedade a quem apresentasse métodos melhores para produção da potassa.

\section{A memória de Watson: essay III of saline substances}

Como se pode ler em A History of the University of Cambridge, ${ }^{41}$ Richard Watson foi professor de química nessa instituição a partir de 1764; entretanto, em 1771, abandonou a cátedra de química, que não era remunerada, e foi designado professor Régio de Teologia. Mesmo afastado do ensino, continuou a publicar trabalhos científicos originais, principalmente sobre águas minerais e sobre a produção de pólvora ${ }^{42}$ e acabou se tornando mais conhecido como químico que como líder religioso - ele havia se tornado bispo na Igreja Anglicana. A seção que abre a Alographia... é uma tradução extraída de seu trabalho mais conhecido, Chemical essays (1781-1787), ${ }^{43}$ em que inclui o plano geral dos cursos ministrados por ele na universidade, um relato em latim da química dos metais e uma coletânea de todos os artigos que publicou no periódico Philosophical Transactions of the Royal Society.

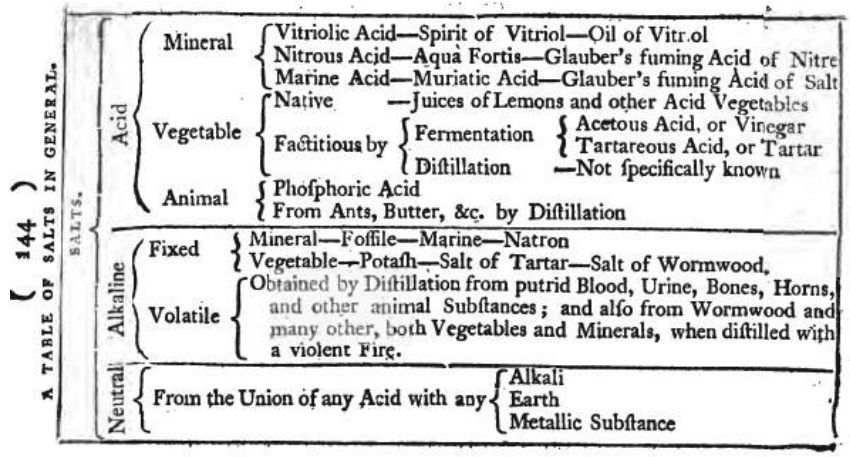

Figura 2. Esquema para explicar os diferentes tipos de sais encontrado no Ensaio III dos Chemical essays (1787) de Richard Watson. Esta Tabela não foi reproduzida por Veloso na sua obra

Além de omitir as tabelas sumarizantes, uma das quais é reproduzida na Figura 2, também não se encontram na tradução de Veloso as três últimas páginas do artigo de Watson. É possível que as tabelas tenham sido introduzidas somente na $4^{\mathrm{a}}$ edição dos Chemical essays (esta a que tive acesso) e Veloso tenha-se utilizado de uma edição anterior. Nas três últimas páginas, Watson discorre sobre duas hipóteses em discussão nas últimas décadas do século XVIII, quando foram publicados os Chemical essays. A primeira hipótese é sobre o ácido vitriólico $\left(\mathrm{H}_{2} \mathrm{SO}_{4}\right)$, que seria o "único princípio salino na natureza e que todos os ácidos e bases seriam somente combinações deste ácido universal com terra, ar, óleo e água, em diferentes proporções". ${ }^{44}$ A segunda hipótese diz respeito à própria composição do ácido vitriólico, que seria formado pela "união íntima entre terra e água". ${ }^{45}$ No Esquema 1, uma tradução livre a partir do livro de texto de Watson, pode-se avaliar como os químicos do século XVIII hierarquizavam os sais conhecidos antes que as definições modernas de ácidos e bases fossem estabelecidas.

\section{A "Flora Alographica"}

A seção final da Alographia... foi denominada "flora alográfica das hervas contheúdas nesta obra, e de outras do Brazil, cuja incineração pode dar huma maior abundancia do Alkali fixo Vegetal, ou Potassa; enriquecida com estampas..." ${ }^{46}$ e contém ilustrações de vinte plantas brasileiras que podiam servir para a produção de potassa pela queima. Na Tabela 3 são listados a nomenclatura empregada por Veloso, assim como seus nomes científicos e comuns usados atualmente.

Apesar de ter sido o autor de Florae Fluminensis, que contava com 1700 estampas originais de plantas do Rio de Janeiro, ${ }^{48}$ aqui Veloso se desculpa pela má qualidade das estampas (Figura 3), que não foram "copiadas de originais vivos, como desejava". ${ }^{49} \mathrm{Na}$ 'flora alographica', escrita como apêndice à Alographia..., Veloso explica como deu o nome sistemático 'Joannesia Princeps' ao andá-açu em homenagem ao Príncipe Regente D. João, a exemplo de botânicos estrangeiros que "se tem lembrado de perpetuar o nome dos seus soberanos em plantas que espontaneamente nascem no Brasil". ${ }^{50}$ Ainda na mesma seção atribui a um "douto brasileiro, advogado nesta corte (Mendes de Oliveira)" experiências para extração da fécula da banana, e de João Manso Pereira (ca. 1750-1820), autor de Considerações sobre as cinzas do cambara, do imbé e do caité etc. publicado por Veloso em $1800,{ }^{51}$ escreve que estava empenhado na obtenção de potassa a partir da bananeira. Veloso também aconselha "aos que resolverem no Brasil a formar potassarias, a que experimentem a combustão de Fetos [samambaias] entalecidos, queimando-os sobre si, e extrahindo das suas cinzas separadamente a potassa", e para auxiliar os que "Ordinariamente se queixao no Brasil de verem que as suas terras cançadas só produzem Fetos" inclui uma lista somente das espécies de fetos do gênero Polypodium. ${ }^{52}$
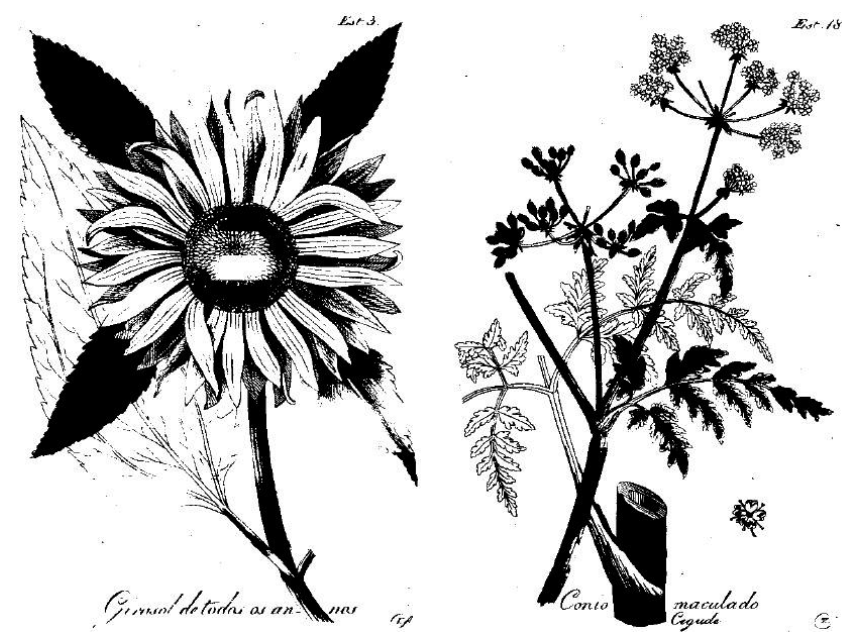

Figura 3. Duas das estampas contidas na 'Flora alographica' onde Veloso apresenta ao leitor as plantas a partir das quais se pode produzir potassa: 'Girassol de todos os annos' à esquerda e 'Conio maculado; cegude', ou cicuta, à direita ${ }^{53}$ 


\begin{tabular}{|c|c|c|c|c|c|}
\hline & & & ácido vitri & espírito do vitrío & leo de vitríolo \\
\hline & & Mineral & ácido nitroso, & tis, ácido de nitr & legante de Glauber \\
\hline & & & ácido marinho, á & rriático, ácido de & Imegante de Glauber \\
\hline & & & nativo & suco de limões & os vegetais ácidos \\
\hline & ácidos & Veretol & & formentoc $\tilde{0}$ & $\begin{array}{c}\text { ácido acético ou } \\
\text { vinagre }\end{array}$ \\
\hline & & vegetal & factível por & termentaçao & $\begin{array}{c}\text { ácido tartáreo ou } \\
\text { tártaro }\end{array}$ \\
\hline & & & & destilação & desconhecido \\
\hline 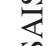 & & A nimol & & ácido fosfórico & \\
\hline & & Animal & de $\mathrm{f}$ & manteiga, etc. & stilação \\
\hline & & Five $>$ & mineral & fóssil- & ho-natrão \\
\hline & & ГIXO & vegetal & potassa - sal de & o - sal de artemísia \\
\hline & alcalinos & Volátil & $\begin{array}{l}\text { Obtido por destil } \\
\text { substâncias anin } \\
\text { vegetais como m }\end{array}$ & $\begin{array}{l}\text { sangue podre, } \mathrm{u} \\
\text { ambém de artem } \\
\text { quando destilad }\end{array}$ & $\begin{array}{l}\text { ssos, chifres e outras } \\
\text { muitas outras, tanto } \\
\text { m um fogo violento. }\end{array}$ \\
\hline & & & & & álcali \\
\hline & neutros & & nião de qualquer á & m qualquer & terra \\
\hline & & & & & substância metálica \\
\hline
\end{tabular}

Esquema 1. Versão para a língua portuguesa do esquema explicativo de Richard Watson mostrado na Figura 2 publicado no Chemical Essays, de 1787

Tabela 3. Plantas representadas por Veloso em sua Flora alographica $^{47}$

\begin{tabular}{|c|c|c|}
\hline nome comum & $\begin{array}{c}\text { nomenclatura } \\
\text { usada por Veloso }\end{array}$ & $\begin{array}{c}\text { nome científico } \\
\text { atual/família }\end{array}$ \\
\hline $\begin{array}{l}\text { cutieira, } \\
\text { andá-açu }\end{array}$ & Joannesia principe & Joannesia princeps Vell. \\
\hline fura-parede & Parietaria officinalis & Parietaria officinalis L. \\
\hline girassol & Helianthus annus & Helianthus annuus L. \\
\hline abrótano & $\begin{array}{l}\text { Artemisia Absyn- } \\
\text { thium Losna }\end{array}$ & Artemisia absynthium L. \\
\hline $\begin{array}{l}\text { fumária, } \\
\text { fel-da-terra }\end{array}$ & Fumaria Officinalis & Fumaria officinalis L. \\
\hline embaúba & Cecropia peltata & Cecropia peltata $\mathrm{L}$. \\
\hline fumo & Nicotiana tabacum & Nicotiana tabacum $\mathrm{L}$. \\
\hline verbasco & Verbascum thapsus & Verbascum thapsus L. \\
\hline $\begin{array}{l}\text { castanha-da- } \\
\text { índia }\end{array}$ & $\begin{array}{l}\text { Aesculus Hyppocas- } \\
\text { tanum }\end{array}$ & Aesculus hippocastanum $\mathrm{L}$. \\
\hline feto macho & Polypodium filix mas & Polypodium filix-mas L. \\
\hline milho & Zea mais & Zea mays L. \\
\hline $\begin{array}{l}\text { marroio- } \\
\text { branco }\end{array}$ & Marrubium vulgare & Marrubium vulgare L. \\
\hline bananeira & Musa paradisiaca & Musa paradisiaca L. \\
\hline tapiá & Crateva tapia & Crateva tapia $\mathrm{L}$. \\
\hline$?$ & Polypodium spinosum & $\begin{array}{l}\text { Dryopteris carthusiana } \\
\text { (Vell.) H.P. Fuchs }\end{array}$ \\
\hline urtiga & Urtica dioica & Urtica dioica $\mathrm{L}$. \\
\hline $\begin{array}{l}\text { meimendro- } \\
\text { negro }\end{array}$ & Hyosciamus niger & Hyoscyamus niger L. \\
\hline cicuta-maior & Conium maculatum & Conium maculatum L. \\
\hline $\begin{array}{l}\text { heliotrópio, } \\
\text { tornassol }\end{array}$ & $\begin{array}{l}\text { Heliotropium Euro- } \\
\text { paeum }\end{array}$ & Heliotropium europaeum L. \\
\hline $\begin{array}{l}\text { borragem, } \\
\text { borago }\end{array}$ & Borrago officinalis & Borrago officinalis L. \\
\hline
\end{tabular}

\section{CONCLUSÕES}

O atraso no desenvolvimento da indústria no Brasil causado, principalmente, pela proibição das atividades manufatureiras decretada por D. Maria I, em 1785, tinha de ser revertido rapidamente por causa da migração da corte para o Rio de Janeiro e, portanto, além de capital e de mão-de-obra, era necessária a tecnologia cuja divulgação o governo português passou a estimular pela publicação de obras como a que discutimos aqui. Um dos aspectos mais significativos para quem examina a extensa obra de Veloso é a diversidade de temas de que tratou, apesar de não ter formação universitária na Europa, como era usual entre os outros grandes nomes da ciência brasileira do século XVIII. O livro pesquisado é um significativo exemplo de ciência sofisticada sendo praticada por um brasileiro no século XVIII e constitui forte argumento para desafiar o mito de que não havia ciência no Brasil colonial, ou que as atividades daquela época eram 'pré-científicas'. No livro de frei Veloso vê-se a Ciência como a conhecemos hoje, reunindo, num mesmo volume, as melhores referências das autoridades da época com descrições de observações próprias, e exemplos múltiplos do diálogo travado entre Veloso e os autores ingleses e franceses por meio de notas de pé de página, escritas de próprio punho, acrescidas aos textos traduzidos. Do aspecto historiográfico, é notável a maneira como os historiadores do Brasil e de Portugal, ao longo do século XIX, tratam de forma diversa a atuação controversa à frente da tipografia do Arco do Cego: os brasileiros nem sequer a mencionam, enquanto os portugueses chegam a reproduzir cartas e outros documentos para atacar a gestão de Veloso frente à tipografia. ${ }^{54}$

\section{AGRADECIMENTOS}

À FAPERJ, ao Prof. J. Schripsema por informações para a Tabela 3, e aos Profs. O. Rios, W. Waldman e P. M. Martins pelas valiosas sugestões.

\section{REFERÊNCIAS}

1. Carneiro, A.; Simões, A.; Diogo, M. P.; Social Studies of Science 2000, 
30, 591; Wehling, A.; Wehling, M. J. C.; Formação do Brasil colonial, Nova Fronteira: Rio de Janeiro, 1994, p. 151; Ferraz, M. H. M.; Quim. Nova 1995, 18, 500; Nizza da Silva, M. B.; Ciênc. Cult. 1988, 40, 859; Ferraz, M. H. M.; As ciências em Portugal e no Brasil, 1772-1822: o texto conflituoso da química, EDUC: São Paulo, 1997, p. 78-91.

2. Gudger, E. W.; Isis 1924, 6, 269.

3. Na verdade, os egípcios já fabricavam vidro em larga escala desde a Décima-oitava Dinastia (1550-1295 A.E.C.) de acordo com Shortland, A. J.; Tite, M. S.; Ewart, I.; Archeometry 2006, 48, 153.

4. No capítulo 51 do livro 28 de Naturalis Historia, Plínio escreve que "sabão, também, é muito útil para este propósito, sendo uma invenção dos gauleses para dar cor avermelhada ao cabelo. Esta substância é preparada a partir de sebo e cinzas, sendo as melhores cinzas para este propósito as da faia e do olmeiro: há dois tipos, o sabão duro e o líquido, ambos muito usados pelo povo da Alemanha, particularmente os homens, mais que as mulheres". No original, obtido em http:// penelope.uchicago.edu/Thayer/L/Roman/Texts/Pliny_the_Elder /28*. html, acessada em junho de 2007, lê-se: "prodest et sapo, Galliarum hoc inventum rutilandis capillis. fit ex sebo et cinere, optimus fagino et caprino, duobus modis, spissus ac liquidus, uterque apud Germanos maiore in usu viris quam feminis."

5. Antonil, A. J.; Cultura e opulência do Brasil por suas drogas, e minas, Museu do Açúcar: Recife, edição facsimilar, 1969, p. 59: "A cinza das fornalhas serve para fazer decoada, e esta para alimpar ao caldo da cana nas caldeiras, e para que saia o açúcar mais forte. Para isso, arrasta-se com rodo de ferro até a boca das fornalhas, pouco a pouco, a cinza e borralho, e daí, com uma pá de ferro, se tira e se leva sobre a mesma pá para o cinzeiro, que é um tanque de tijolo [...] se lhe bota água, tirada de um tacho grande, que está fervendo sobre a sua proporcionada fornalha, perto do cinzeiro. E para isso serve a água que passa pela bica e vai à casa das caldeiras; e coando esta água pela cinza, até passar pelos buracos que têm as tinas no fundo cobra o nome de decoada".

6. Roberts III, W. I.; Proceedings of the American Philosophical Society 1972, 116, 383.

7. Velloso, J. M. da C.; Alographia dos alkalis fixos vegetal ou potassa, mineral ou soda e dos seus nitratos, segundo as melhores memorias estrangeiras, Que se tem escripto a este assumpto. parte primeira; Offic. de Simão Thaddeo Ferreira: Lisboa, 1798.

8. Pode-se ler, por exemplo, no relato de 1578 de Jean de Léry (15341611): "Um dos nossos companheiros indo lavar camisas deitou por ignorância cinzas dessa madeira [pau-brasil] na lixívia; em vez de alvejá-las esta as tornou tão vermelhas que não achamos meio de tirarlhes a coloração embora as tivéssemos lavado e ensaboado logo em seguida; e tivemos de usá-las assim com essa tintura.”; Léry, J.; Viagem à terra do Brasil, Edusp, Martins: São Paulo, 1972, p. 125.

9. Martins, W.; História da inteligência brasileira, vol. 1: 1550-1794, T. A. Queiroz: São Paulo, 1992, p. 74.

10. Impressão Régia, Gazeta do Rio de Janeiro 1811, 50, 4.

11. Nasceu e foi batizado José Veloso Xavier na atual Tiradentes - MG em 1741 e era primo de Tiradentes. Faleceu em 13 de junho de 1811 no convento de Santo Antônio no Rio de Janeiro em cujo claustro ficou sepultado.

12. Do convento, localizado na Fazenda Macacu, no município de ItaboraíRJ, nos fundos da baía de Guanabara, só restam ruínas.

13. Cañizares-Esguerra, J.; Isis 2005, 96, 64.

14. Damasceno, D. [in] Veloso, Frei J. M. da C.; Plantas Fluminensesdesenhos de Muzzi, Biblioteca Nacional: Rio de Janeiro, 1976, p. 6.

15. Pinto de Souza, J. C.; Bibliotheca Histórica de Portugal, Typographia Chalcographica, Typoplastica, e Litteraria do Arco do Cego: Lisboa, 1801, p. 54 do anexo I; Lagos, M. F.; "Elogio Histórico do Padre Mestre Fr. José Marianno da Conceição Velloso"; Revista do Instituto Histórico e Geographico Brazileiro, tomo $2^{\circ}, 2^{\mathrm{a}}$ ed., 1858, p. 596; Nunes, M. de F.; Brigola, J. C. Em A casa literária do Arco do Cego
(1799-1801) - Bicentenário: "sem livros não há instrução"; de Campos, F. M. G.; Curto, D. R.; Cunha, M.; Leme, M. O. R. P.; Tudela, A. P., eds.; Imprensa Nacional-Casa da Moeda - Biblioteca Nacional: Lisboa. 1999, p. 63; Blake, A. V. A. S.; Diccionario bibliographico brazileiro, 5 vols., Typographia Nacional: Rio de Janeiro, 1899, p. 64.; Azevedo, F. de; Cultura Brasileira, $4^{\text {a }}$ ed., 1964, p. 255.; Belluzzo, A. M. de M.; O Brasil dos viajantes, Metalivros: São Paulo, 1994, vol. 2, p. 159; Grande Enciclopédia Portuguesa e Brasileira; Editorial Enciclopédia: Lisboa Rio de Janeiro, vol. 34, 1981, p. 510.

16. Carrara Jr., E.; Meirelles, H.; A indústria química e o desenvolvimento do Brasil, Metalivros: São Paulo, 1996, tomo I, p. 31.

17. Reilly, D.; Isis 1951, 42, 287.

18. Thompson, C. J. S.; Lure and Romance of Alchemy, George G. Harrap \& Co. Ltd: London, 1932 (Kessinger Publishing, 2003), p. 64.

19. Duhamel du Monceau, H.-L.; Suite des Mémoires de mathematique et de physique tire des registres de l'Academie Royale des Sciences de l' année 1736, Pierre Mortier: Amsterdam, 1740, p. 299.

20. Daintith, J.; Mitchell, S.; Tootill, E.; Gjertsen, D.; Biographical Encyclopedia of Scientists, $2^{\text {nd }}$ ed, vol. 1, Institute of Physics Publishing: Bristol, 1994, p. 241.

21. Allen, R. C.; David Hartley on Human Nature; Suny Press: Albany, 1999, p. 64.

22. O escocês Joseph Black deu o passo seguinte, quando em 1775 estabeleceu a diferença entre os álcalis suaves (carbonatos) e os álcalis cáusticos (hidróxidos). Ele dizia que a soda e a potassa comuns eram compostas do dióxido de carbono com a soda cáustica e a potassa cáustica, respectivamente, de acordo com Hilditch T. P.; A Concise History of Chemistry, Van Nostrand: New York, 1911, p. 64.

23. Diderot, D.; D’Alembert, J., orgs.; Encyclopédie ou dictionnaire raisonné des sciences, des arts et des métiers, tome 13, Chez Samuel Faulche \& Cie: Neufchastel, 1765, p. 178.

24. No original lê-se: "ce mot est originairement allemand; il signifie cendre de pot, \& a été adopté en françois \& en anglois, pour désigner un sel alkali fixe qui se tire des cendres de différens bois brûlés, on donne aussi le nom de potasse à la cendre même qui contient ce sel alkali fixe; cette cendre est rendue compacte \& solide comme une pierre, parce qu'on l'humecte pour cet effet avec de l'eau, après quoi on la calcine pour la durcir...".

25. Almeida, A. V.; Magalhães, F. O.; Quim. Nova 1997, 20, 445.

26. Arruda da Câmara, M.; Memórias Econômicas da Academia Real das Ciências, vol. IV, Lisboa, 1814, p. 83-93.

27. Forsythe, W.; The International Journal of Nautical Archaeology 2006, $35,218$.

28. Veloso aponta numa nota de pé de página na sua tradução do ensaio de Watson que os espanhóis usam dois termos para se referir à sodabarrilha, para o produto mais puro e soza para as inferiores.

29. Pérez, J. F.; Tascón, I. G.; La agricultura viajera, cultivos y manufacturas de plantas industriales y alimentarias en España y en la América Virreinal, Consejo Superior de Investigaciones Científicas: Madrid, 1990, p. 214.

30. Arruda da Câmara, M.; op. cit.

31. Dajic, Z. Em Physiology and Molecular Biology of Stress Tolerance in Plants; Madhava Rao, K. V.; Raghavendra, A. S.; Janardhan Reddy, K. eds.; Springer: Dordrecht, 2006, cap. 3, p. 44.

32. Sociedade Auxiliadora da Indústria Nacional; O Auxiliador da Industria Nacional 1833, 1, 21.

33. Velloso, J. M. da C. Em ref. 7, p. 97.

34. Na última página desta parte primeira, onde há um "catálogo dos livros que se tem impresso [...] de ordem de Sua Alteza Real [...], dirigindo Fr. José Mariano da conceição Velloso, informa-se que os outros dois tomos desta série sobre os álcalis, ou seja, o segundo volume sobre a soda e o terceiro sobre o salitre, foram publicados nesse mesmo ano de 1798, sendo um na mesma gráfica de Simão Thaddeo e outro na Officina 
Patriarchal de João Procopio Correa da Silva. Entretanto, não consegui encontrar estes dois volumes nem na Biblioteca Nacional nem no Real Gabinete Português de Leitura, ambos no Rio de Janeiro.

35. Wegner, R.; Hist. Ciênc. Saúde-Manguinhos 2004, 11 supl. 1, 131.

36. Velloso, J. M. C.; op. cit., p. xv.

37. Webster's Encyclopedic Unabridged Dictionary of the English Language, Gramercy: New York, 1994, p. 640.

38. Velloso, J. M. C.; op. cit., p. vii.

39. Museum Rusticum et Commerciale: or, Select papers on agriculture, commerce, arts, and manufactures Drawn from experience, and communicated by gentlemen engaged in these pursuits, R. Davis: London, 1765, p. 409.

40. Roberts III, W. I.; Proceedings of the American Philosophical Society 1972, 116, 383.

41. Searby, P.; Leader, D. R.; Morgan, V.; A History of the University of Cambridge, vol III (1750-1870), University Press: Cambridge, 2004, p. 218.

42. Thornburn Burns, D.; Microchim. Acta 2003, 142, 143.

43. Watson, R.; Chemical Essays, 5 volumes, várias editoras, 1781-1787; (11 edições).

44. "...vitriolic acid is the only saline principle in nature, all other acids, and alkalies being nothing but combinations of this universal acid with earth, air, oil and water, in different proportions."; Watson, R.; Chemical Essays, vol. 1, 4ª. ed., T. Evans: Londres, 1787, p. 146.

45. "...an intimate union of earth and water."; ibid.

46. Velloso, J. M. C.; op. cit., p. 191.

47. Sampaio, A. J., Peckolt, O.; Arquivos do Museu Nacional 1943, 37, 331.

48. Ferri, M. G. Em As ciências no Brasil; Azevedo, F. de, ed.; Editora UFRJ: Rio de Janeiro, 1994, vol. 2, cap. X, p. 182.

49. Velloso, J. M. C.; op. cit., p. vii.

50. Velloso, J. M. C.; op. cit., p. 196.

51. Varnhagen, F. A.; Historia Geral do Brazil, Caza de E. e H. Laemmert: Rio de Janeiro, tomo $2^{\circ}$, 1857, p. 477; Filgueiras, C. A. L.; Quim. Nova 1993, 16, 155.

52. Velloso, J. M. C.; op. cit., p. 233.

53. Velloso, J. M. C.; op. cit., p. 207, 238.

54. “deste padre não existe na Impressão Régia senão a memória do dinheiro que lhe ficou devendo; a lembrança de não ter apresentado, apesar de decretos e avisos que lh'o ordenaram, os livros das contas do Arco do Cego" Em Silva, I. F.; Diccionario Bibliographico Portuguez, Imprensa Nacional: Lisboa, tomo 13, p. 125. 